\title{
Intra-Axial Neurenteric Cyst of Medulla. Case Report and Literature Review
}

\author{
Andrey Vladimirovich Gavrjushin, MD, PhD and Danil Mihajlovich Chelushkin, MD* \\ N.N. Burdenko National Medical Research Center of Neurosurgery, Russia

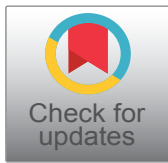

*Corresponding author: Danil Mihajlovich Chelushkin, N.N. Burdenko National Medical Research Center of Neurosurgery, 4 Tverskaya-Yamskayast., 16, Moscow, 125047, Russia, Tel : +79-017-433-551

\begin{abstract}
Background: NECs are rare congenital lesions that are thought to be a result of persistence of the neurenteric canal to arise from a persistent neurenteric canal connecting primitive gut and neural tube. Despite the congenital nature NECs can be diagnosed at any age and at a similar frequency in women and men. To our knowledge, 140 intracranial NC, confirmed by histology, including the patient presented in this review, have been reported since 1952. Parenchymal NCs are extremely rare and there are no any publications describing the intra-axial NECs of brainstem at the moment.

Case description: A 19-year-old female presented to the clinic with complaints of moderate dysphagia (2-3 times per day) for and liquids and solids, dysphonia, vertigo, spontaneous nystagmus, imbalance and numbness of the left side of body including face. The MRI of the brain showed a well-defined lesion cantered in the medulla. The patient underwent right-sided keyhole retrosigmoid approach through small craniotomy. Just under the sulcus cyst containing pathological amorphous gray-yellow liquid was evacuated. Accessible parts of capsula was resected without brain injury. Residual particles of capsula were coagulated. Two month after operation patient presented with similar symptoms. We used previous craniotomy during second surgery. After evacuation of the cyst the silicone stent was set for connecting with cerebellopontine cistern and preventing new synechiae formation. As surely as after first surgery all neurological symptoms were gradually regressing. In two months after surgery deglutition and sensations recovered, hemiparesis and imbalance has decreased. Postoperative MRI examination two months after surgery shows no evidence of cyst recurrence.
\end{abstract}

Conclusion: Intra-axial NC - rare group of congenital pathological lesions with favourable prognosis. There are not any publications of brainstem's NCs with intra-axial localization to date. The treatment of choice in this group of patients is complete microsurgical excision with following long-term observation.

\section{Keywords}

Intra-axial cyst, Cyst of medulla, Neurenteric cyst

\section{Abbreviations}

CNS: Central Nervous System; CPA: Cerebellopontine Angle; KS: Karnofsky Scale; NC: Neurenteric Cyst; PCF: Posterior Cranial Fossa; VPS: Ventriculoperitoneal Shunting

\section{Background}

Firstly, NC was described in 1928 by Kubie [1] and in 1934 by Pussep [2]. From this time it is known as: Enterogenic Cyst, Endodermal Sinus Cyst, Intestinal Cyst, Teratomatous Cyst, Intestinoma and Archenteric Cyst [3].

NECs are rare congenital lesions that are thought to be a result of persistence of the neurenteric canal to arise from a persistent neurenteric canal connecting primitive gut and neural tube. As a result of separation failure of the canal NEC cavity lined with cuboidal or columnar epithelium and contains mucin-producing cells [3-6].

Nowadays with regard to morphological similarity NECs, Rathke Clef Cysts and Colloid Cyst belong to one general group - Endodermal Cysts of CNS.

This "Seessel's pouch origin" hypothesis suggests a common origin for suprasellar NC, Rathke's cleft cysts and colloid cysts, seems not to be perfect because it fails to explain laterally positioned S-NC.

The other existing non-comprehensive theory includes embryonal failure of separation between the notochord and the foregut leading to incorporation of primitive endodermal cells in the notochord. However, as the most rostral extent of the endoderm terminates

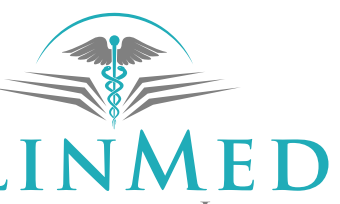

Citation: Gavrjushin AV, Chelushkin DM (2021) Intra-Axial Neurenteric Cyst of Medulla. Case Report and Literature Review. Neurosurg Cases Rev 4:065. doi.org/10.23937/2643-4474/1710065

Accepted: April 21, 2021; Published: April 23, 2021

Copyright: (c) 2021 Gavrjushin AV, et al. This is an open-access article distributed under the terms of the Creative Commons Attribution License, which permits unrestricted use, distribution, and reproduction in any medium, provided the original author and source are credited. 
at the level of the clivus, this hypothesis does not explain the occurrence of spinal NECs.

To date the most likely hypothesis suggests that a migration defect causes endodermal cells to pass through the primitive neurenteric canal into the ectoderm, thus reaching far cranial and lateral positions [4-8].

According to different authors, NC is comprising from $0.15 \%$ to $0.35 \%$ of all intracranial lesions, $0.3 \%$ to $0.5 \%$ of spinal tumors and approximately $16 \%$ of CNS cysts $[3,9,10]$.

Despite the congenital nature NECs can be diagnosed at any age and at a similar frequency in women and men. Compared with intraspinal NCs, which usually occur in the paediatric age groups, intracranial NCs are more common in the adult population, in the third and fourth decade. The average age of patients diagnosed with intracranial NC is 34 years old $[3,5,11,12]$.

To our knowledge, 140 intracranial NC, confirmed by histology, including the patient presented in this review, have been reported since 1952 .

Since 1952 to 2012 years there were 140 cases of NCs reported in the literature totally $[2,3,9,10,13-16]$.

The majority of neurenteric cysts occur in the spine, usually ventral to the spinal cord. Intracranial neuren- teric cysts are far less common. Intracranial locations are predominantly infratentorial anterior to the brainstem, at the cerebellopontine angle and to a lesser extent within the cisterna magna and the fourth ventricle. Parenchymal NCs are extremely rare [5-8,17] and there are not any publications describing the intra-axial NECs of brainstem at the moment.

For this reason, we present our clinical impression.

\section{Case Description}

A 19-year-old female presented to the clinic with complaints of hoarseness and mild dysphagia for liquids, symptoms had been gradually deteriorating symptoms for 5 months. At the moment of hospitalization physical examination shows moderate dy sphagia (2-3 times per day) for and liquids and solids, dysphonia, vertigo, spontaneous nystagmus, imbalance and numbness of the left side of body including face.

The MRI of the brain showed a well-defined lesion centered in the medulla. This lesion was homogeneously hypointense on T2-weighted images and heterogeneously hypointense on T1-weighted images and demonstrated no solid enhancing components. It was also heterogeneous lyhypo intense on DWI. PET-CT did not reveal metabolic activity in this lesion (Figure 1).
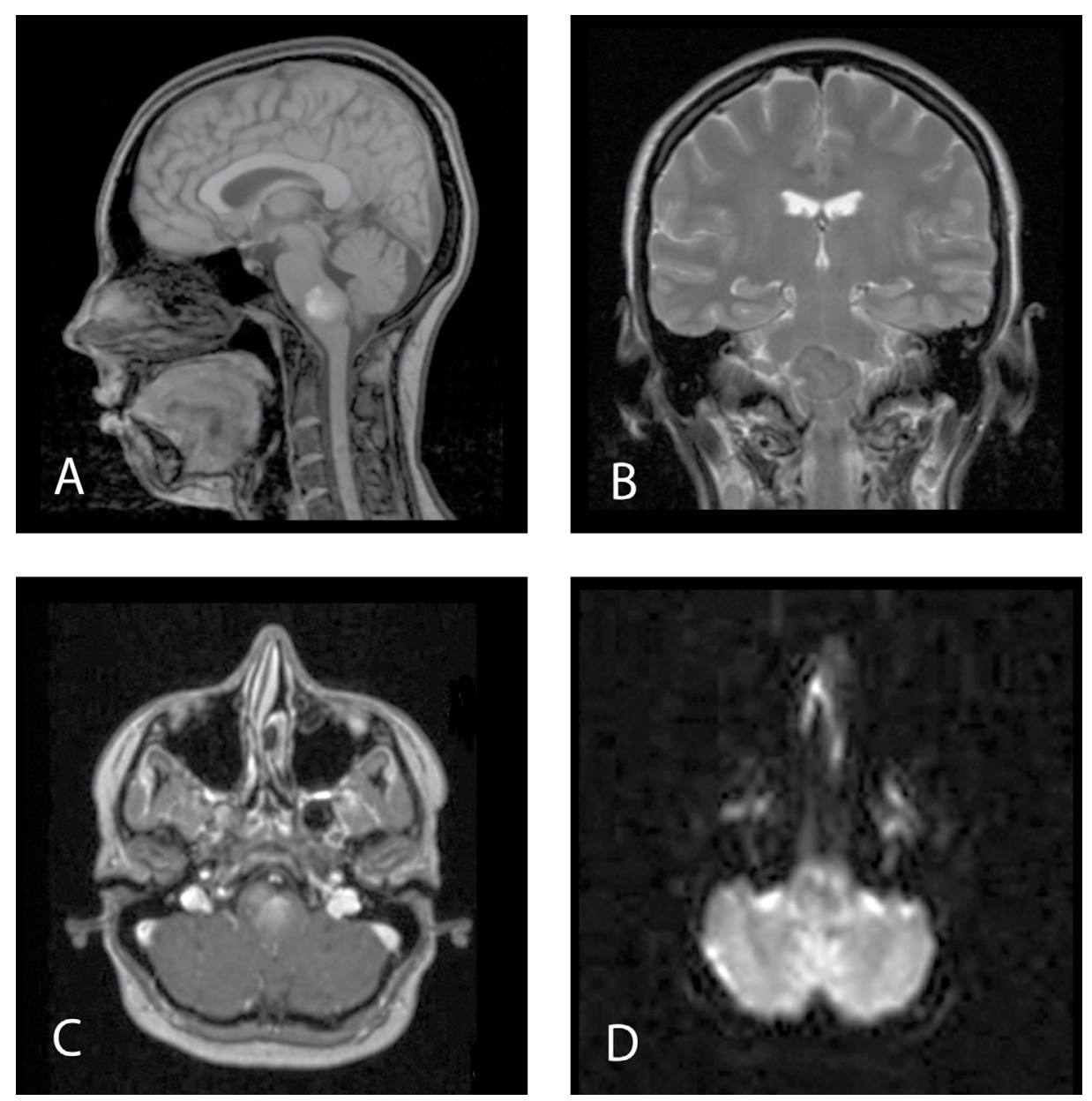

Figure 1: MRI before first surgery. A) MRI T1 sagittal view; B) MRI T2 frontal view; C) MRI T1 + contrast, axial view; D) MRI DWI. 
The patient underwent right-sided keyhole retrosigmoid approach in supine position with rotation of head to the left due to radiologic (closest medulla surface) and clinical (right-sided neurological symptoms dominance) features. Through small craniotomy $(2 \times 1 \mathrm{sm}$.) and little $C$-shaped dura incision along the sigmoid sinus towards the skull base the medulla surface was archived. It was deformed and bulging into cerebellopontine cistern. There were no signs of brain parenchima destruction on the surface. So the brainstem incision was made in small region (almost $0.3 \mathrm{sm}$.) along the retroolivary sulcus. Just under the sulcus cyst containing patological amorphous gray-yellow liquid was evacuated. Cyst's paries present thin gray capsula tighly attached to surrounding brain parenchima. Accessible parts of capsula were resected without brain injury. Residual particles of capsula were coagulated. We did not perform additional endoscopic revision of cyst's cavity due to surgical accessibility of cavity. We used transcranial motor evoked potentials and caudal brainstem mapping during the operation.

Numbness of the left side of body and all clinical signs from PCF increased after surgery at a time when dysphagia and dysphonia increased. Postoperative CT did not reveal any remaining parts of cyst, decrease of medulla dislocation was mentioned.

All neurological symptoms almost regressed in one month after operation including numbness. KS was 90 .

Two months after operation patient presented with mild dysphagia and dysphonia, vertigo, spontaneous nystagmus, imbalance and numbness of the left side of body and right limb including face and mild left-sided hemiparesis before MRI was planned.

Result of MRI revealed reccurence of the cyst. As it was before the lesion had well-defined, heterogeneously hyper- and isointense on T1-weighted images, demonstrated no solid enhancing components but homogeneously hyperintense on T2-weighted images now. Sites of hyperintesity were less pronounced than on MRI before the first surgery (Figure 2).

We used previous craniotomy during the second surgery. The site of brainstem incision was covered with arachnoidal synechias leads to white viscous formless fluid accumulation (Figure 3). After evacuation of the cyst the silicone stent was set for connecting with cerebellopontine cistern and preventing new synechias
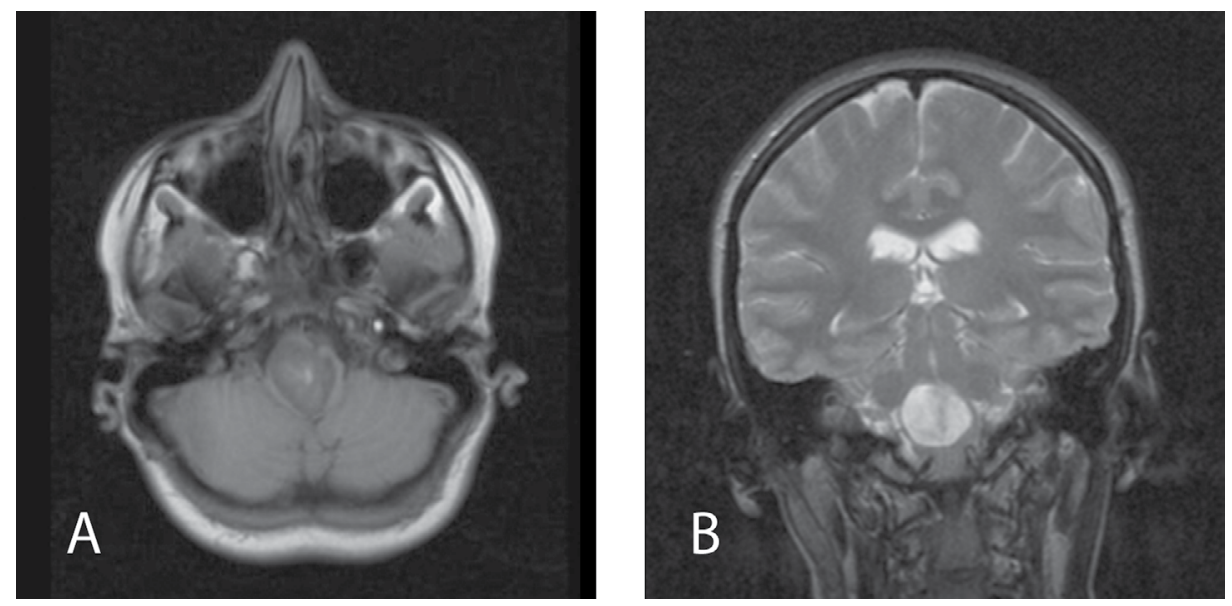

Figure 2: MRI 2 months after first surgery. A) MRI T1 axial view; B) MRI T2 frontal view.
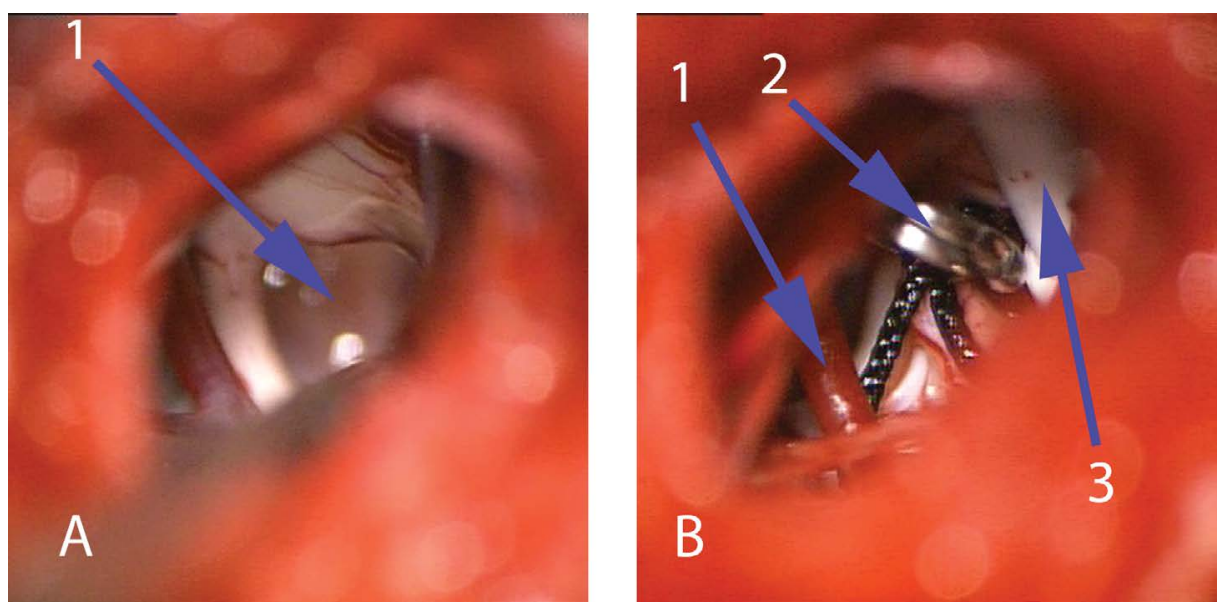

Figure 3: Intraoperative view during second surgery. A) View before evacuation of the cyst on the bottom of brainstem along the retroolivary sulcus, 1 - White viscous formless fluid into cyst; B) View after evacuation of the cyst, 1 - Posterior inferior cerebellar artery 2 - Clip fixates stent to arachnoidea, 3 - Stent in the cavity of cyst). 

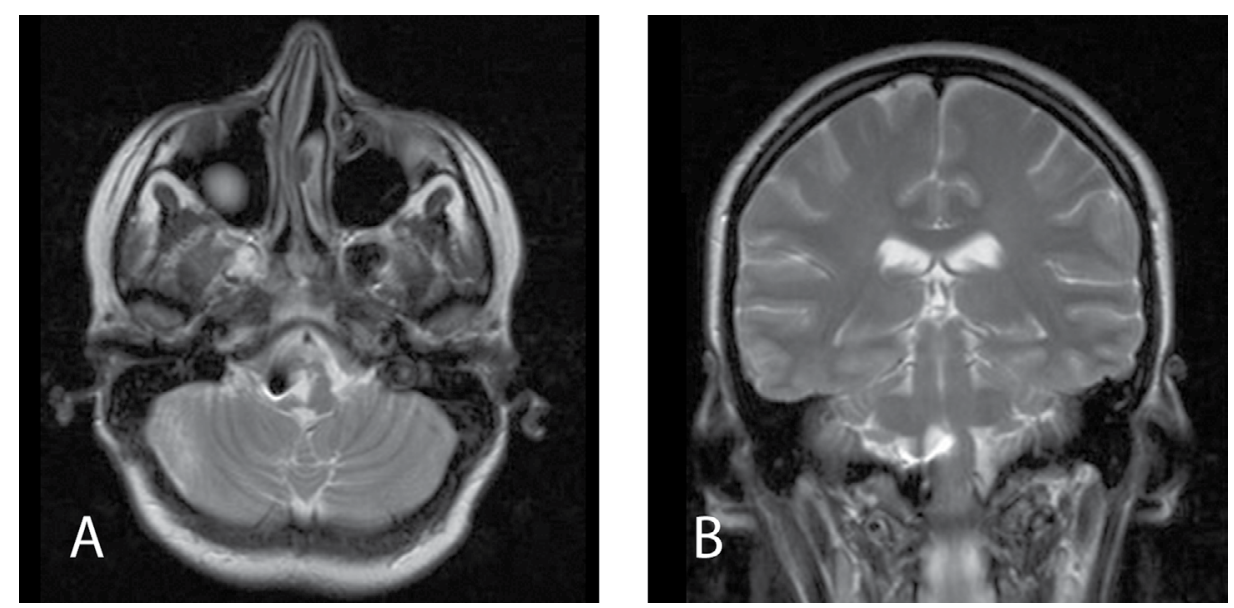

Figure 4: MRI 2 months after second surgery. A) MRI T2 axial view, black point - place of mini-clip's location; B) MRI T2 frontal view, stent in the cavity of cyst).

formation. Stent was fixated to arachnoidea with single clip.

As surely as after first surgery all neurological symptoms were gradually regressing. In two months after surgery deglutition and sensations recovered, hemiparesis and imbalance has decreased.

Postoperative MRI examination two months after surgery shows no evidence of cyst reccurence (Figure 4).

Histological material after first and second surgery presents yellow-white gelatinous liquid with small parts of epithelial lining seeing microscopically. The morphological appearance intraoperatively and histological findings were in keeping with the diagnosis of NC.

\section{Conclusion}

NC is rare congenital abnormality of CNS most likely localizing in inferior cervical and superior thoracic the spinal canal. Most of the intracranial NCs localize in PCF in basal cysterns, craniocervical junction or IV ventricle. Parenchymal localization is extremely rare $[5-8,17]$.

MRI examination is a method of choice in the diagnostic algorithm of NC but its characteristics can be variable. It shows well-demarcated lesions iso- or tightly hypointense in $\mathrm{T} 1$ and hyperintense in T2-weighted sequences and FLAIR $[5,6,8,17,18]$. NCs usually demonstrate no contrast enhancement but Prasad, et al. reported mild posterior rim enhancement that can be explained by chronic inflammatory changes due to repeated cyst rupture in their view [19]. In our case MRI characteristics were not typical. Before the first the surgery lesion was heterogeneously hyperintense on T1-weighted imagesand homogeneously hypointense on T2-weighted images (Figure 1). Before second surgery MRI characteristics have changed. It was hyperintense in $\mathrm{T} 2$ and sites of hyperintesity in $\mathrm{T} 1$ were less pronounced than before the first surgery (Figure 2) that is most likely for NCs. Such change of signal can be explained by high concentration in liquid cyst cavity. It led to heterogeneously hyperintense on T1-weighted im- ages and homogeneously hypointense on T2-weighted images before first operation.

NCs are slow growing benign lesions. NC can compress surrounding neural structures during it's enlargement. It leads to such clinical signs due to anatomical localization.

The treatment of choice is complete surgical excision. Clinical signs regress after surgery in large part. Although radical resection will prevent recurrence, in view of the very thin firmly adherent capsule to the brainstem, it is not always possible to do complete resection capsule without any neurological deficits, especially in PCF $[4,5,8,17]$.

Kozak, et al. [5] described case series operated in period from 2010 to 2018. There were 4 cases of NCs located in superior cervical part of spinal cord extramedullary, 3 cases intracranially in craniocervical junction and IV ventricle and left frontal lobe. In all spinal cases they achieved total removal while in 2 intracranial cases (craniocervical junction and IV ventricle) they were forced to leave fragment of capsule due to firmly adhesion with vessels and pia mater.

In case series of Wang, et al. [20] 7 cases with NCs were described and 6 of the localized anteriorly extra-axially to brain stem from medulla to $\mathrm{C} 1$ segment of spinal cord and 1 case in CPA. Gross total resection was achieved in 3 cases only.

Besides problems with radical resections lots of authors write about necessity of relapse surgery in cases with early recurrence of NC from capsule remnants. Nelson, et al. [6] shows clinical case of huge NC of CPA, IV ventricle and foramen Luschka. In this case gross total resection was not achieved due to firm adhesion with brainstem and cisternal segments of IX-XI cranial nerves. Later due to recurrence of NC clinical signs had progressed and VP shunting 1 month after surgery, and relapse surgery with partial removal in 4 months was required. 
Chen, et al. [4] showed 10 cases with NCs in their large series. 5 of them were spinal extramedullary and 5 - intracranially (temporal and frontal lobe, CPA). Gross total resection was achieved in 4 cases of 10. In 6 cases of subtotal resection recurrence of NC was in 4 cases. Relapse surgery including resection of recurrent cyst, VP or cyst peritoneal shunting due to clinical signs worsening only in 3 patients.

Opposed to clinical case series above in our case the reason of recurrence was firmly adhesion in brainstem incision area so we place silicone stent aidits drainage in cerebellopontine cistern.

In the current literature $\mathrm{NCs}^{\prime}$ recurrence could occur a long time after surgery too. However, sequela quantity is hard to be ranged due to rare occurrence of NCs. Only Chavda, et al. mentioned sequela quantity after subtotal resection of NCs in their case series as $37 \%$ with 30 year follow-up [21].

To date there is a consensus of many authors' opinion that patients require long time follow-up with regular MRI examination and relapse surgery in case of recurrence with clinical signs worsing [5].

Intra-axial NC - rare group of congenital pathological lesions with favourable prognosis. There are not any publications of brainstem's NCs with intra-axial localization to date.

The treatment of choice in this group of patients is complete microsurgical excision with following longterm observation.

\section{Financial Statement}

The work in it's entirety was funded by the authors. No financial disclosures.

\section{Previous Presentation of Work}

None.

\section{Declarations of Interest}

None.

\section{Conflict of Interest}

The authors declare that they have no conflict of interest.

\section{References}

1. Kubie LS (1928) A Clinical and pathological study of two teratomatous cyst of the spinal cord, containing mucous and ciliated cells. Gynecol Obstet Surgery 47: 297-311.

2. Shimizu Y, Fujita N, Akiyama O, Suzuki M, Kondo A (2019) A rare presentation of a pediatric neurenteric cyst as an intra-axial pontine lesion: A case report with a 5-year follow-up. Surg Neurol Int 10: 236.

3. Perry A (2013) Practical surgical neuropathology: A diagnostic approach, 2nd edition. J Chem Inf Model.

4. Chen CT, Lai HY, Jung SM, Lee CY, Wu CT, et al. (2016) Neurenteric cyst or neuroendodermal cyst? Immunohisto- chemical study and pathogenesis. World Neurosurg 96: 85-90.

5. Kozak J, Bizik I, Surkala J, Steno J, Steno A (2019) Neurenteric cysts, incidence and surgical treatment. Bratisl Lek Listy 120: 680-685.

6. Nelson SM, Mathis DA, Hobbs JK, Timpone VM (2017) Intracranial neurenteric cyst mimicking an ependymoma: Imaging features, pathologic correlation and review of literature. Clin Imaging 44: 117-120.

7. Agrawal M, Dharanipathy S, Nakra T, Garg K, Gurjar H, et al. (2019) Supratentorial neurenteric cyst: A rare differential for a frontal cyst. World Neurosurg 129: 140-142.

8. Goes P, Vaz-Guimaraes F, Suriano IC, Araujo S, Zymberg ST (2018) Supratentorial neurenteric cyst: Analysis of 45 cases in the literature. Interdiscip Neurosurg Adv Tech Case Manag 11: 57-64.

9. Breshears JD, Rutkowski MJ, McDermott MW, Cha S, Tihan T, et al. (2015) Surgical management of intracranial neuroenteric cysts: The UCSF experience. J Neurol Surg B Skull Base 76: 475-479.

10. Gauden AJ, Khurana VG, Tsui AE, Kaye AH (2012) Intracranial neuroenteric cysts: A concise review including an illustrative patient. J Clin Neurosci 19: 352-359.

11. Gu J, Yang T, Xing X, Kuang Y, Cheng G, et al. (2015) A dorsally located giant posterior fossa neurenteric cyst in a Chinese woman. J Clin Neurosci 22: 917-918.

12. Zalatnai A (1987) Neurenteric cyst 01 medulla oblongata A Curiosity. Neuropediatrics 18: 40-41.

13. Agresta G, Sokol D, Kaliaperumal C, Kandasamy J, Gallo P (2020) A novel management proposal for intrinsic brainstem neurenteric cysts: Case report. J Neurosurg Pediatr 25: 83-87.

14. Cho JM, Ahn JY, Kim SH, Lee KS, Chang JH (2010) An endodermal cyst mimicking an intra-axial tumor in the medulla oblongata. Child's Nerv Syst 26: 853-856.

15. Lach B, Russell N, Atack D, Benoit B (1989) Intraparenchymal Epithelial (Enterogenous) Cyst of the Medulla Oblongata. Can J Neurol Sci 16: 206-210.

16. Li T, Wu X, Zhang Y (2017) A rare presentation of an enterogenous cyst as an Intra-axial pontine lesion. World Neurosurg 100 .

17. Shimanskiy VN, Shevchenko KV, Poshataev VK, Odamanov DA, Karnaukhov VV, et al. (2017) Intracranial neurenteric cysts: Experience of the burdenko neurosurgical institute in the XXIth Century. Zh Vopr Nejrokhir Im NN Burdenko 81: 16-24.

18. Yılmaz O, Duymus M, Yigit H, Asal N (2011) MRI follow up of intracranial endodermal cysts. Child's Nerv Syst 27: 861-862.

19. Prasad GL, Sharma BS, Mahapatra AK (2015) Ventral foramen magnum neurenteric cysts: A case series and review of literature. Neurosurg Rev 39: 535-544.

20. Wang L, Zhang J, Wu Z, Jia G, Zhang L, et al. (2011) Diagnosis and management of adult intracranial neurenteric cysts. Neurosurgery 68: 52.

21. Chavda SV, Davies AM, Cassar-Pullicino VN (1985) Enterogenous cysts of the central nervous system: A report of eight cases. Clin Radiol 36: 245-251. 